\title{
The lemur baseline: How lemurs compare to monkeys and apes in the Primate Cognition Test Battery
}

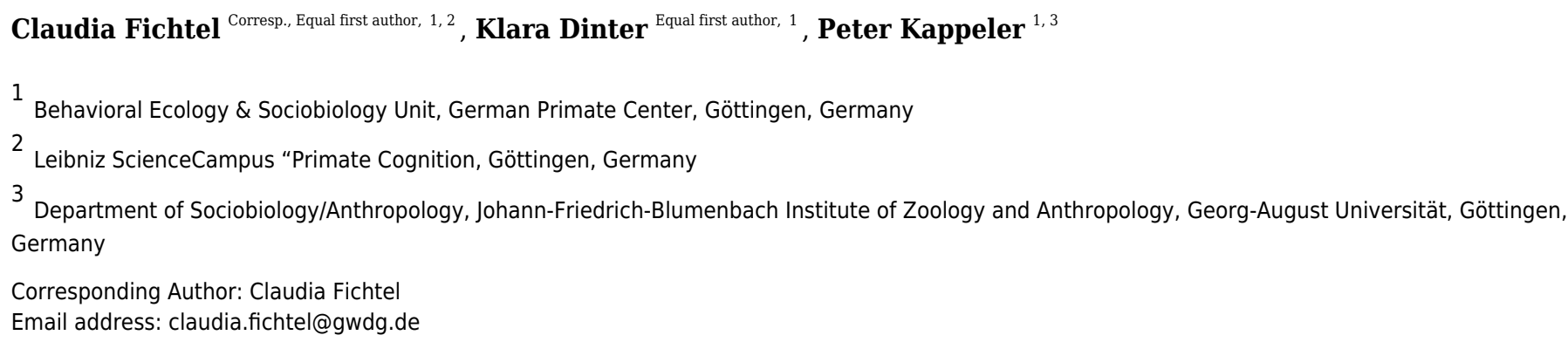

Primates have relatively larger brains than other mammals even though brain tissue is energetically costly. Comparative studies of variation in cognitive skills allow testing of evolutionary hypotheses addressing socioecological factors driving the evolution of primate brain size. However, data on cognitive abilities for meaningful interspecific comparisons are only available for haplorhine primates (great apes, Old- and New World monkeys) although strepsirrhine primates (lemurs and lorises) serve as the best living models of ancestral primate cognitive skills, linking primates to other mammals. To begin filling this gap, we tested members of three lemur species (Microcebus murinus, Varecia variegata, Lemur catta) with the Primate Cognition Test Battery, a comprehensive set of experiments addressing physical and social cognitive skills that has previously been used in studies of haplorhines. We found no significant differences in cognitive performance among lemur species and, surprisingly, their average performance was not different from that of haplorhines in many aspects. Specifically, lemurs' overall performance was inferior in the physical domain but matched that of haplorhines in the social domain. These results question a clear-cut link between brain size and cognitive skills, suggesting a more domain-specific distribution of cognitive abilities in primates, and indicate more continuity in cognitive abilities across primate lineages than previously thought. 
1 The lemur baseline: How lemurs compare to monkeys and apes in the Primate Cognition

2 Test Battery

3

4 Claudia Fichtel $^{1,2}$, Klara Dinter ${ }^{1}$ and Peter M. Kappeler ${ }^{1,3}$

5

$6 \quad{ }^{1}$ Behavioral Ecology \& Sociobiology Unit

7 German Primate Center, Göttingen, Germany

8

9 2Leibniz ScienceCampus "Primate Cognition”, Göttingen, Germany

10

$11{ }^{3}$ Department of Sociobiology/Anthropology

12 Johann-Friedrich-Blumenbach Institute of Zoology and Anthropology, Georg-August Universität

13 Göttingen, Germany

14

15 Corresponding author: claudia.fichtel@gwdg.de

16 Author's contributions: C.F. and K.D. have a shared first-authorship, they conceived the study and

17 analysed the data.

18

19 ORCIDs:

20 Claudia Fichtel: 0000-0002-8346-2168

21 Klara Dinter: 0000-0002-0339-3036

22 Peter Kappeler: 0000-0002-4801-487X

23

24

25

Peer] reviewing PDF | (2020:04:48269:1:3:NEW 10 Aug 2020) 


\section{ABSTRACT}

31 Primates have relatively larger brains than other mammals even though brain tissue is energetically costly. Comparative studies of variation in cognitive skills allow testing of evolutionary hypotheses addressing socioecological factors driving the evolution of primate brain size.

34 However, data on cognitive abilities for meaningful interspecific comparisons are only available 35 for haplorhine primates (great apes, Old- and New World monkeys) although strepsirrhine 36 primates (lemurs and lorises) serve as the best living models of ancestral primate cognitive skills,

37 linking primates to other mammals. To begin filling this gap, we tested members of three lemur 38 species (Microcebus murinus, Varecia variegata, Lemur catta) with the Primate Cognition Test 39 Battery, a comprehensive set of experiments addressing physical and social cognitive skills that

40 has previously been used in studies of haplorhines. We found no significant differences in 41 cognitive performance among lemur species and, surprisingly, their average performance was not 42 different from that of haplorhines in many aspects. Specifically, lemurs' overall performance was 43 inferior in the physical domain but matched that of haplorhines in the social domain. These results 44 question a clear-cut link between brain size and cognitive skills, suggesting a more domain45 specific distribution of cognitive abilities in primates, and indicate more continuity in cognitive 46 abilities across primate lineages than previously thought.

48 Keywords: cognition, Primate Cognition Test Battery, primates, lemurs 


\section{INTRODUCTION}

51 One central question in comparative cognition is why primates have evolved larger brains and

52 superior cognitive skills compared to other equally-sized mammalian species (Shettleworth 2010).

53 Among primates, this effect is paralleled by a disproportionate increase in brain size from

54 strepsirrhines to haplorhines and humans (Dunbar 1992; Isler et al. 2008; Jerison 1973; Martin

55 1981). Because larger brains are energetically more expensive (Aiello and Wheeler 1995), they

56 are assumed to confer benefits with regard to enhanced cognitive abilities that compensate this

57 additional investment (Navarrete et al. 2011; Reader and Laland 2002; Reader et al. 2011).

58 Several non-mutually exclusive hypotheses on the evolution of brain size have been

59 proposed to account for the distinctive cognitive abilities of primates (Dunbar and Shultz 2017).

60 According to the General intelligence hypothesis, larger brains are thought to confer an advantage

61 because of faster learning and larger memory capacities (Spearman 1904). The Ecological

62 intelligence hypothesis suggests that environmental and ecological challenges in food acquisition,

63 including spatial and spatio-temporal processes to memorize seasonally available food or

64 manipulative skills for extractive foraging, selected for larger brains (Byrne 1996; Clutton-Brock

65 and Harvey 1980; Heldstab et al. 2016; Milton 1981; Powell et al. 2017). Several versions of the

66 Social brain hypothesis posit that increased cognitive skills in primates evolved in response to the

67 constant challenges associated with the complexity of social life, such as competition and 68 cooperation within larger social groups (Byrne and Whiten 1988; Dunbar 1992; Dunbar and Shultz 69 2007; Humphrey 1976; Jolly 1966a; Kudo and Dunbar 2001). However, support for the Social

70 brain hypothesis is not uniform in other taxa, with brain size correlating positively with measures

71 of sociality in some insectivores, bats and ungulates (e.g. Barton et al. 1995; Byrne and Bates

72 2010; Dunbar and Bever 1998; Shultz and Dunbar 2006), but not in corvids (Emery et al. 2007; 
73 Shultz and Dunbar 2007), and it is equivocal in carnivores (Benson-Amram et al. 2016; Dunbar

74 and Bever 1998; Finarelli and Flynn 2009; Holekamp et al. 2007; Pérez-Barbería et al. 2007).

75 Moreover, recent comparative analyses among primates indicated that brain size is associated with

76 ecological (home range size, diet, activity period), but not with social factors (DeCasien et al.

77 2017; Powell et al. 2017), also challenging the social brain hypothesis.

78 Since these studies usually link interspecific variation in brain size with certain socio-

79 ecological factors, it is essential to understand how brain size actually impacts cognitive skills.

80 Hence, comparative studies of cognitive abilities, ideally using identical tests, across the primate

81 order and beyond are required. However, comparisons of performance in cognitive experiments

82 across species may fail due to variation in the experimental set-up and specific methods (van Horik

83 and Emery 2011; Krasheninnikova et al. 2019; MacLean et al. 2012; Schubiger et al. 2020).

84 To overcome this problem, Herrmann and colleagues (2007) assembled a systematic

85 toolbox for comparative analysis, called the Primate Cognition Test Battery (PCTB), which

86 compared cognitive skills in various tasks in the physical and social domain among 2.5 -year-old

87 children, chimpanzees (Pan troglodytes) and orangutans (Pongo pygmaeus). The physical domain

88 deals with the spatial-temporal-causal relations of inanimate objects, while the social domain deals

89 with the intentional actions, perceptions, and knowledge of other animate beings (Tomasello and

90 Call 1997). These tests revealed that children and chimpanzees have similar cognitive skills for

91 dealing with the physical world, but children have increased cognitive skills for dealing with the

92 social world, particularly in the scale of social learning. These results support the Cultural

93 intelligence hypothesis, a variant of the Social brain hypothesis, suggesting that exchanging

94 knowledge within human cultural groups requires specific socio-cognitive skills, such as social

95 learning or Theory of Mind (e.g. Boyd and Richerson 1998; Herrmann et al. 2007; Whiten and van 
96 Schaik 2007). The PCTB has been replicated in another population of chimpanzees, and this study

97 also indicated that variation in cognitive performance is heritable (Hopkins et al. 2014).

98 Application of the PCTB to two other haplorhine species, long-tailed macaques (Macaca

99 fascicularis) and olive baboons (Papio anubis), revealed that both species performed similarly to

100 great apes in both the physical and the social domain (Schmitt et al. 2012). Specifically,

101 chimpanzees outperformed macaques only in tasks on spatial understanding and tool use. Since

102 chimpanzees have relatively larger brains than macaques or baboons (Isler et al. 2008; Jerison

103 1973), these results question the clear-cut relationship between cognitive performance and brain

104 size (Schmitt et al. 2012). In addition, four closely related macaque species that differ in their

105 degree of social tolerance, performed similarly in tests of the PCTB in the physical domain.

106 However, socially more tolerant species performed better in one task of the social domain and the

107 inhibitory control task, suggesting that social tolerance is associated with a set of cognitive skills

108 that are specifically required for cooperation (Joly et al. 2017). Thus, further studies on additional

109 non-human primates are required to explore the interrelationships among cognitive abilities, socio-

110 ecological traits and brain size (ManyPrimates et al. 2019a,b).

111 Strepsirrhine primates are the obvious candidates for such an extended comparative

112 approach because they represent the best living models of the earliest primates and the link

113 between primates and other mammalian orders (Fichtel and Kappeler 2010; MacLean et al. 2008).

114 Strepsirrhines split off from the main primate lineage approximately 60 million years ago and

115 retained many ancestral primate traits (Martin 1990; Yoder et al. 1996; Yoder and Yang 2004).

116 Importantly, strepsirrhine primates have relatively smaller brains than haplorhines, and their brain

117 size does not correlate with group size (MacLean et al. 2009). Although older studies suggested

118 that strepsirrhine primates possess physical cognitive abilities that are inferior to those of 
119 haplorhines (e.g. Ehrlich et al. 1976; Jolly 1964; Maslow and Harlow 1932), recent studies

120 indicated that their cognitive skills are similar to those of haplorhines (e.g. Deppe et al. 2009;

121 Fichtel and Kappeler 2010; Kittler et al. 2015, 2018; Santos et al. 2005a, b). However, existing

122 studies of strepsirrhine cognition used isolated tests, hampering systematic interspecific

123 comparisons. Hence, a comprehensive study investigating a broad variety of tasks addressing

124 different cognitive skills in lemurs, and replicating the exact same methods used in the PCTB,

125 seems warranted for a systematic comparison across both primate suborders.

126 To this end, we applied the PCTB to three species of lemur that differ in key socio-

127 ecological traits: ring-tailed lemurs (Lemur catta), black-and-white ruffed lemurs (Varecia

128 variegata; hereafter: ruffed lemurs) and gray mouse lemurs (Microcebus murinus, Table 1). Mouse

129 lemurs have one of the smallest brains among primates, and absolute brain size increases from

130 mouse lemurs over ring-tailed lemurs to ruffed lemurs (Isler et al. 2008). Ring-tailed lemurs are

131 diurnal opportunistic omnivores that live in groups of on average 14 individuals (Gould et al. 2003;

132 Jolly 1966b; Sussman 1991). Ruffed lemurs are diurnal, frugivorous and live in small groups

133 (average 6 individuals), exhibiting a fission-fusion social organization (Baden et al. 2015; Holmes

134 et al. 2016; Vasey 2003). Gray mouse lemurs are nocturnal, omnivorous solitary foragers that form

135 sleeping-groups composed of related females (Eberle and Kappeler 2006; Isler et al. 2008).

136 According to the General intelligence hypothesis, we predicted that the tested apes and

137 monkeys outperform lemurs because they have absolutely larger brains (Table 1). In accordance

138 with the Ecological intelligence hypothesis we predicted that the more frugivorous species or those

139 with a broader dietary breadth perform better (Table 1). Because lemurs generally live in smaller

140 groups than monkeys and apes (Kappeler and Heymann 1996), we predicted that they should have 
141 inferior cognitive abilities than the already tested group-living species according to the Social

142 intelligence hypothesis (Table 1).

143

144

145

\section{METHODS}

147 Experiments were conducted with adult individuals of gray mouse lemurs $(\mathrm{n}=9-15)$, ring-tailed

148 lemurs $(n=26-27)$ and black-and-white ruffed lemurs $(n=13)$. All individuals were born in captivity

149 and housed in enriched or semi-natural environments, either at the German Primate Centre (DPZ,

150 Göttingen) or the Affenwald Wildlife Park (Straußberg, Germany). The lemurs at the Affenwald

151 range freely within a 3.5 ha natural forest enclosure. At the DPZ, ring-tailed and ruffed lemurs are

152 offered indoor and outdoor enclosures equipped with enriching climbing materials and natural

153 vegetation. The nocturnal mouse lemurs are kept indoors with an artificially reversed day-night-

154 cycle, and their cages are equipped with climbing material, fresh natural branches and leaves. All

155 individuals were tested individually in their familiar indoor enclosures and were trained to indicate

156 their choice by touching or reaching for the chosen object, but were naîve to the presented tasks.

157 Since some individuals passed away during the course of the study, not all individuals participated

158 in every task of the test battery (Table S1, Supplemental). To ensure comparability with the

159 previous studies, the experimental setup was replicated after the PCTB (Herrmann et al. 2007;

160 Schmitt et al. 2012), and only objects presented in the tests were adjusted in size for lemurs.

161

\section{Ethical statement}

163 All animal work followed relevant national and international guidelines. The animals were kept under conditions documented in the European Directive 2010/63/EU (directive on the protection 
165 of animals used for experimental and other scientific purposes) and the EU Recommendations

166 2007/526/EG (guidelines for the accommodations and care of animals used for experimental and

167 other scientific purposes). Consultation and approval of the experimental protocols by the Animal

168 Welfare Body of the German Primate Center is documented (E2-17).

169

170 General testing procedure

171 During the experiments, individuals were briefly separated from the group. The testing apparatus

172 for all tasks consisted of a table with a sliding board on top that was attached to the mesh of the

173 subjects' enclosures (Figure S2, Supplemental). In most of the tasks two or three opaque cups

174 (ruffed- \& ring-tailed lemurs: $\varnothing 6.8 \mathrm{~cm}$ x $7.5 \mathrm{~cm}$; mouse lemurs: $\varnothing 2.5 \mathrm{~cm}$ x $3 \mathrm{~cm}$ ), which were

175 placed upside down in a row on the sliding board, were used to cover the food reward (see also

176 Supplemental). If necessary, a cardboard occluder was put on top of the sliding board between the

177 experimental setup and the individual to hide the baiting process from the individuals. The position

178 of the reward was randomized and counter-balanced across all possible locations, and the reward

179 was never put in the same place for more than two consecutive trials. Once the board was pushed

180 into reach of an individual, the experiment began, and, depending on the task, the individual had

181 to manipulate an item or indicate its choice by pointing or reaching towards the chosen item, to

182 obtain the reward if chosen correctly. If the choice was incorrect, the correct location of the reward

183 was shown to the individual after each trial.

184 For most of the tasks at least 6 trials were conducted per individual and setup (Table S1,

185 Supplemental). Raisins and pieces of banana served as rewards. During testing, no possible cues

186 to where the reward was located were provided by the experimenter; she simply put her hands on

187 her lap and her gaze was directed downwards. All experiments were videotaped and responses of 
188 the subjects to the tasks coded afterwards from the videos. A naïve second observer additionally

189 scored $20 \%$ of all trials a second time to assess inter-observer reliability. The Interclass Correlation

190 Coefficient was excellent $(\mathrm{ICC}=0.985)$.

191

192

193

194 The Primate Cognition Test Battery

195 All experimental setups and methods were replicated from the PCTB (Herrmann et al. 2007;

196 Schmitt et al. 2012). Following Schmitt et al. (2012), we also doubled the number of trials for all

197 object-choice tasks of the test battery (Table S1, Supplemental) to evenly distribute objects

198 between all possible spatial positions and combinations of manipulations. In total, the PCTB

199 consists of 16 different experimental tasks, 10 investigating physical and 6 social cognitive skills.

200 These tasks can be grouped into 6 different scales: space, quantities and causality for the physical

201 and social learning, communication and Theory of Mind for the social domain.

202 In the physical domain, the space scale examines the ability to track objects in space in

203 four tasks: spatial memory, object permanence, rotation and transposition. The quantities scale

204 tests the numerical understanding of individuals and consists of two tasks: relative numbers and

205 addition numbers. The causality scale consists of four tasks: noise, shape, tool use and tool

206 properties to examine the ability to understand spatial-causal relationships. In the social domain,

207 the social learning scale examines in one task whether individuals use social information provided

208 by a human demonstrator to solve a problem. The communication scale examines whether

209 individuals are able to understand communicative cues given by humans in three tasks:

210 comprehension, pointing cups and attentional state. Finally, in the Theory of Mind scale, 
211 individuals were confronted with two tasks: gaze following and intentions. A detailed description

212 of the general setup and the methodology of the experiments can be found in the supplementary

213 material (Supplemental).

214

215 Temperament, inhibitory control, rank and learning effect

216 To assess the influence of temperament, inhibitory control and dominance rank on lemurs'

217 performances in the test battery, individuals participated in a set of additional tests (Herrmann et

218 al. 2007; Schmitt et al. 2012). Due to logistic constraints, the temperament tests could only be

219 conducted with ring-tailed and ruffed lemurs. For temperament, we measured whether individuals

220 would approach novel objects, people and foods (for details see Supplemental). Inhibitory control

221 was measured during an additional session of the spatial memory task, in which out of three cups

222 only the two outer ones were baited with a reward, and, hence, individuals had to skip the cup in

223 the middle. Dominance rank (high, middle or low-ranking) was inferred by focal observations of

224 ring-tailed and ruffed lemurs but not for the solitary mouse lemurs, according to Pereira and

225 Kappeler (1997). We also controlled for potential learning effects within the trials of a task by

226 calculating Pearson's correlations between performance in the first and second half of trials.

228 Data analyses

229 We measured the performance of individuals by the proportion of correct responses for each task.

230 We applied Wilcoxon tests followed by Benjamini-Hochberg corrections (for multiple testing) for

231 each task and lemur species to examine whether they performed above chance level. Since no

232 individual solved the social learning task and only one the tool use task, we omitted both tasks

233 from the interspecies comparisons. To analyse whether the three lemur species differed in their 
234 performance in the tasks of the PCTB, we used multivariate analysis of variance (MANOVA) with

235 species, sex, rank, age and age:species as between-subject factor and their performance in all tasks

236 as dependent variable. To compare all three species' performances between the different tasks, we

237 used univariate analysis of variance (ANOVA, for normally distributed data) or Kruskall-Wallis

238 tests followed by post hoc analyses (with Bonferroni correction). For significant results, we used 239 an analysis of covariance (ANCOVA) to control for age in these tasks.

240 Comparisons of performance in tests of the PCTB were conducted between the three lemur 241 species and four haplorhine species (chimpanzees, orangutans, olive baboons, and long-tailed 242 macaques) for which data on individual performance were kindly provided by E. Herrmann and 243 V. Schmitt. On the scale level, we applied a MANOVA, followed by ANOVAs or Kruskall-Wallis 244 tests and post hoc corrections (Bonferroni) in case of significant results. All statistical analyses 245 were conducted in R version 3.2.2 (R Core Team, Vienna, Austria).

\section{RESULTS}

\section{Lemurs' performance in the physical and social domain}

249 In the physical domain, the chance level was at $33 \%$ in all four tasks of the space scale. The three 250 lemur species performed significantly above chance level in the spatial memory and the rotation 251 task (Table 2, Fig. 1). In the object permanence tasks, only ruffed lemurs performed above chance

252 level, while in the control task, all three species performed above chance level (Table 2, Fig. 1). In 253 the quantities scale, the three lemur species performed significantly above chance level (50\%) in 254 both tasks (Table 2, Fig. 1). In the causality scale, the tool use task was successfully solved by 255 only one ring-tailed lemur. However, in the shape and tool properties tasks, all three lemur species 256 performed above chance level (50\%; Table 2). 
258 demonstrated by a human experimenter (Table 2, Fig. 1). In the communication scale, all three

259 lemur species performed significantly above chance level (50\%) in the comprehension task,

260 whereas only mouse lemurs performed above chance level (50\%) in the pointing cups task. All

261 lemur species performed poorly in the attentional state task. In the Theory of Mind scale, none of

262 the lemur species did follow the gaze of the human experimenter upwards significantly more often

263 than in the control condition in which no cue was given (baseline: 20\%; Table 2, Fig. 1). In

264 contrast, all lemur species performed significantly above chance level (50\%) in the intentions task

265 (Table 2, Fig. 1).

266

267 Influence of age, sex and rank on performance of the three lemur species

268 Because the tool use task was solved by only one individual and the social learning task by none, 269 these two tasks were excluded from this comparison. A multivariate analysis of variance of the 14 270 remaining tasks revealed no differences in the average performance among the three lemur species 271 (MANOVA; Wilk's $\Lambda=0.498, F(19,14)=1.37, \mathrm{p}=0.257$ ). Furthermore, average performance was 272 not influenced by sex (Wilk's $\Lambda=0.461, F(19,14)=1.59, \mathrm{p}=0.173$ ), rank (Wilk's $\Lambda=0.273$, $273 F(38,28)=1.24, \mathrm{p}=0.268)$, age $($ Wilk's $\Lambda=0.568, F(19,14)=1.03, \mathrm{p}=0.466)$ or age within species 274 (age:species; Wilk's $\Lambda=0.599, F(19,14)=0.91, \mathrm{p}=0.566$ ).

275

276 Personality, inhibitory control and learning

277 The three temperament measures (latency, proximity and duration) of ring-tailed or ruffed lemurs

278 did neither correlate with the performance in the physical domain of the PCTB (Pearson's 279 correlations, all $\mathrm{p}>0.05$, see Supplemental), nor with the performance of ring-tailed lemurs in the 
280 social domain. In ruffed lemurs, however, the latency to approach and proximity to a novel 281 stimulus correlated with performance in the social domain (latency to approach: Pearson's 282 correlation, $r(11)=0.61, \mathrm{p}=0.026$; proximity: Pearson's correlation, $r(11)=-0.59, \mathrm{p}=0.032)$. No 283 correlation was found between the time individuals spent close to the setup (duration) and 284 performance (Pearson's correlation, $r(11)=-0.30, \mathrm{p}=0.323$ ). Performance in the inhibitory control 285 task did not correlate with performance in the physical and social domain (see Table S4, 286 Supplemental). In addition, we did not find a learning effect in performance between the first and 287 second half of trials within the tasks (Wilcoxon Signed-Rank test: V=806.5, $\mathrm{p}=0.585$ ).

\section{Comparison of lemurs and haplorhines in the physical and social domain}

292 The comparison of chimpanzees, orangutans, baboons, macaques, ruffed-, ring-tailed- and mouse 293 lemurs in their overall average performance in the two domains revealed differences among 294 species (Wilk's $\Lambda=0.383, F(406,12)=20.87, \mathrm{p}<0.001$ ). Species differed in performance in the 295 physical domain (Kruskal-Wallis, $\chi^{2}=127.26$, $\mathrm{df}=6, \mathrm{p}<0.001$; Fig. 2 ), but not in the social domain 296 (Kruskal-Wallis, $\chi^{2}=10.25, \mathrm{df}=6, \mathrm{p}=0.115$; Fig. 2). In the physical domain, only chimpanzees 297 performed significantly better than ruffed lemurs, and chimpanzees and orangutans outperformed 298 ring-tailed and mouse lemurs (see Table S4, Supplemental).

\section{Comparison of lemurs and haplorhines in the different scales}

301 For a more detailed comparison of all seven species, we conducted a MANOVA including each

302 individuals' overall performance in all six scales, which revealed significant differences among 
303 species (Wilk's $\Lambda=0.284, F(833,36)=7.68, \mathrm{p}<0.001)$. Species differed in all scales except the

304 communication scale (ANOVAs or Kruskal-Wallis tests, see Table 3; Fig. 3). In the space scale,

305 chimpanzees outperformed all other species, except baboons. Orangutans performed better than

306 ruffed and ring-tailed lemurs, baboons performed better than all three lemur species, and macaques

307 performed similar to all lemur species (Table 4; Fig. 3). In the quantities scale, only chimpanzees

308 performed better than ring-tailed lemurs (Table 4; Fig. 3), and in the causality scale, chimpanzees

309 outperformed all other species, and orangutans performed better than mouse lemurs (Table 4; Fig.

310 3). However, this scale was strongly biased by the results of the tool use task, which was only

311 solved by chimpanzees, orangutans and one ring-tailed lemur. Excluding the tool use task from

312 this comparison revealed that only chimpanzees performed better than mouse lemurs (Table 4;

313 Fig. S2, Supplemental).

314 In the social domain, all species, except great apes, performed poorly in the social learning

315 task, whereas all species performed equally well in the communication scale (Table 4; Fig. 3). In

316 the Theory of Mind scale, however, chimpanzees performed less well than macaques and ring-

317 tailed lemurs. All other species performed better than orangutans, except mouse lemurs and

318 macaques, and ring-tailed lemurs outperformed mouse lemurs (Table 4; Fig. 3).

320 DISCUSSION

321 In this study, we applied the Primate Cognition Test Battery to three lemur species differing in

322 socioecological traits and brain size and compared their performance with that of four haplorhine

323 species tested in previous studies with the exact same methods. In the physical domain, apes and

324 baboons performed better than lemurs in the space scale, chimpanzees performed better than ring-

325 tailed lemurs in the quantities scale and better than mouse lemurs in the causality scale, after 
326 excluding the tool use task. In the social domain, lemurs performed at level to apes and monkeys.

327 Most interestingly, in the Theory of Mind scale, great apes were outperformed by all other species

328 except mouse lemurs. Since these species differ in relative and absolute brains size (Table 1), with

329 a more than 200-fold difference in brain size between mouse lemurs and orangutans or

330 chimpanzees, our results do not support the notion of a clear-cut link between brain size and

331 cognitive skills, but suggest a more domain-specific distribution of cognitive abilities in primates.

332 In the physical domain, lemurs were outperformed by apes and baboons in the space scale.

333 The species with the largest brains (apes and baboons) performed better than all other species,

334 supporting the General intelligence hypothesis. These findings are in line with an earlier study

335 showing that apes and monkeys differ in their ability to track object displacements (Amici et al.

336 2010). Spatial understanding is also important to remember food resources or to track conspecifics

337 (Dunbar and Shultz 2017), and species (chimpanzees, orangutans, baboons) having a larger dietary

338 breadth performed better in these tasks, but the species with the highest amount of fruits in the diet

339 (ruffed lemurs) did not perform better than other species, providing only partial support for the

340 Ecological intelligence hypothesis. There was no clear pattern between group size and

341 performance in the space scale, providing no support for the Social intelligence hypothesis.

342 In the quantities scale, only chimpanzees performed better than ring-tailed lemurs, and all

343 other species performed similarly, indicating that a certain level of numerical understanding

344 appears to be a basal cognitive trait of all primates. These results support earlier studies indicating

345 that lemurs do not differ from haplorhine primates in numerosities and simple arithmetic

346 operations (Jones and Brannon 2012; Merritt et al. 2011; Santos et al. 2005a). Since a comparable

347 numerical understanding as tested in the PCTB has also been reported for various taxa outside the

348 primate order, including fish and insects (e.g. Agrillo et al. 2012; Chittka and Geiger 1995; Pahl 
349 et al. 2013; but see Krasheninnikova et al. 2019), a basal numerical understanding may be present

350 in many animals.

351 In the causality scale, lemurs performed as well as both monkey species, but all monkeys

352 and lemurs were outperformed by chimpanzees, who excelled in the tool use task. Even natural

353 tool users, such as orangutans and long-tailed macaques (Brotcorne et al. 2017; van Schaik et al.

354 2003), hardly solved this task (Schmitt et al. 2012). It required the ability to use a stick to rake a

355 food reward into reach, which might have been too challenging for species exhibiting either a

356 medium (baboons, macaques) or low (lemurs) level of precision grip (Torigoe 1985). Although

357 long-tailed macaques use stone tools to crack open nuts or mussels, they do so mainly by applying

358 force rather than using fine-motor skills (Gumert and Malaivijitnond 2012). Thus, the tool use task

359 appears unsuitable for a fair interspecific comparison. Excluding this task from the causality scale

360 resulted in a rather similar overall average performance of all species. Interestingly, lemurs that

361 have never been observed to use tools in the wild (Fichtel and Kappeler 2010; Kittler et al. 2015,

362 2018), appeared to exhibit an understanding for the necessary functional properties of pulling tools

363 (Santos et al. 2005b; Kittler et al. 2018). Hence, except for the space scale we did not find

364 systematic species differences in performance, challenging the notion that there is a domain-

365 general distinction between haplorhines and strepsirrhines (Deaner et al. 2006). Our results instead

366 suggest the existence of domain-specific cognitive differences.

367 In the social domain, species differences were less pronounced, and lemurs' overall

368 performance in the Theory of Mind scale was equal to that of monkeys and even superior to that

369 of apes. In the social learning scale neither lemurs, nor baboons or long-tailed macaques solved

370 the task. However, long-tailed macaques exhibit cultural variation in stone handling techniques in

371 the wild, indicating that they are able to learn socially (Brotcorne et al. 2017). The ability to learn 
372 socially has also been reported in ring-tailed and ruffed lemurs (e.g. Kappeler 1987; Kendal et al.

373 2010; O'Mara and Hickey 2012; Stoinski et al. 2011), but remains unstudied in mouse lemurs.

374 Since individuals had to learn in this task from a human demonstrator, the phylogenetic distance

375 between species and the demonstrator might have influenced learning abilities, because great apes

376 performed better than Old World monkeys and lemurs (Schmitt et al. 2012). Hence, it remains an

377 open question whether monkeys and lemurs would perform better when tested with a conspecific

378 demonstrator. Moreover, the task required the ability to shake a transparent tube or to insert a stick

379 into the tube, which might have been too difficult for species with limited dexterity (Torigoe 1985).

380 Therefore, a social learning task demonstrated by a conspecific and adapted to manipulative skills

381 of Old World monkeys and lemurs (Schnoell and Fichtel 2012), posing technical problems that

382 they have to face in their natural environment (Kummer and Goodall 1985), might be more

383 informative in future studies

384 In the communication scale, all species performed equally well, suggesting that all species

385 can make use of socio-visual cues given by others. This result is in line with those of several other

386 studies showing the ability to use social-visual cues presented by a human demonstrator in object-

387 choice experiments in birds (Schmidt et al. 2011), aquatic mammals (sea lions: Malassis and

388 Delfour 2015; dolphins: Tschudin et al. 2001), domestic animals (dogs: Kaminski et al. 2005;

389 Miklósi et al. 1998; pigs: Nawroth et al. 2016; goats: Wallis et al. 2015), as well as other primates

390 (Anderson et al. 1995; Itakura 1996).

391 In contrast, unexpected species differences emerged in the Theory of Mind scale, with great

392 apes performing inferior to both monkeys and lemurs. This difference was mainly due to better

393 performance of monkeys and lemurs in the intentions task, but not in the gaze following task. In

394 the gaze following task, all lemurs performed below chance level, although it has been shown that 
395 ring-tailed lemurs follow the gaze of conspecifics (Shepherd and Platt 2008) and that they use

396 human head orientation as a cue for gaze orientation in a food choice paradigm (Botting et al.

397 2011, Sandel et al. 2011), questioning the validity of these gaze following tasks. In the intention

398 task, a human observer tried to reach a cup with a hidden reward repeatedly with the hand.

399 Monkeys and lemurs might have performed better than apes because they may have solved the

400 task by using spatial associations between the repeated hand movements and the cup or by

401 understanding the hand movements as a local enhancement (Shettleworth 2010; Schmitt et al.

402 2012). Still, it remains puzzling why chimpanzees and orangutans did not use the hand movement

403 as a cue for the location of the hidden reward. Even more so because a comparative study of Theory

404 of Mind compatible learning styles in a simple dyadic game between seven primate species,

405 including chimpanzees and ring-tailed lemurs, and a competitive human experimenter revealed

406 that test performance was positively correlated with brain volume, but not with social group size,

407 suggesting that Theory of Mind is mostly determined by general cognitive capacity (Devaine et al.

408 2017). Hence, additional social cognitive tests are required to obtain a better understanding of the

409 relationship between brain size and cognitive performance in the social domain.

410 Altogether, average species performances were generally not as different as it might have

411 been expected in view of the various hypotheses on the evolution of cognitive abilities. Except for

412 the space scale, the overall comparison did not provide support for the General intelligence

413 hypothesis, since variation in brain size cannot explain the observed results. Similarly,

414 performances of the seven species did not reflect any clear patterns concerning their feeding

415 ecology, i.e. the percentage of fruit in the diet or dietary breadth, except for the space scale (see

416 Table 1); hence, these results did not provide support for the Ecological intelligence hypothesis.

417 Moreover, our results did not provide support for the Social intelligence hypothesis because 
418 lemurs, and especially the solitary mouse lemurs, should have performed inferior compared to the

419 haplorhine species (Dunbar and Shultz 2017).

420 Earlier comparative studies among primates linking performance in a range of comparable

421 cognitive tests in the physical or social domain revealed a link between performance in these tasks 422 and brain size (Deaner et al. 2006, 2007; Reader and Laland 2002; Reader et al. 2011). However, 423 studies using the exact same experimental set up revealed contradictory results. Two studies 424 addressing only one cognitive ability revealed a positive relationship between brain size and 425 performance in inhibitory control or Theory of Mind tests (Maclean et al. 2014; Devaine et al. 426 2017), but all other studies applying various tests on inhibitory control and spatial memory (Amici 427 et al. 2008, 2010, 2012) or tasks of the Primate Cognition Test Battery (Herrmann et al. 2007; 428 Schmitt et al. 2012; this study), found no clear-cut relationship between brain size and cognitive 429 performance.

430 Even though lemurs performed at level with monkeys and great apes in many of these 431 experiments, we do not suggest that their cognitive abilities are per se on par with those of larger432 brained primates. In the physical domain, species differences emerged only in the space scale, 433 with species having larger brains performing better. These findings might provide support for the 434 General intelligence hypothesis but the sample size is rather small to make any firm conclusions. 435 However, no systematic species differences were found in the quantities or causality scales, which 436 might not be variable enough to reveal actual differences between species. Since some fish and 437 insects possess similar basal cognitive skills as tested in the physical domain of the PCTB (Fuss et 438 al. 2014; Loukola et al. 2017; Schluessel et al. 2015), the potential link between brain size and 439 performance in the space scale requires further testing. In the social domain, the social learning 440 task was not suitable for all species, and individuals might have recruited other abilities to solve 
441 the problems, as discussed for the intention task above. Hence, to examine species differences in

442 cognitive abilities, it is necessary to conduct cognitive tests that measure the cognitive abilities

443 they are intended to measure and that are sensitive, i.e. difficult enough to detect variation in 444 cognitive performance without producing ceiling or floor effects (see also Schubiger et al. 2020).

445 In addition, many tests of the PCTB were based on two-or three-choice paradigms in which

446 the costs for choosing correctly were rather low, because the probability to receive a reward was

447 either $50 \%$ or $33 \%$, and a random choice strategy might have been still relatively profitable. For

448 example, performance in a memory task increased in common marmosets (Callithrix jacchus) and

449 common squirrel monkeys (Saimiri sciureus) from a two-choice task to a nine-choice task, in

450 which the probability of success was lowered from $50 \%$ to $11 \%$, making a wrong choice more

451 costly, appeared to favour an appropriate learning strategy over a random choice strategy

452 (Schubiger et al. 2016). The application of a random choice strategy may also explain why four

453 parrot species that were tested with the PCTB, may have failed to solve the tasks, besides

454 morphological differences in performing the tasks (Krasheninnikova et al. 2019).

Finally, the PCTB was designed to examine the spontaneous ability to solve the tasks, and not to examine how long individuals need to learn the task. Hence, a test battery that continued testing until individuals reached a certain criterion (e.g. $80 \%$ correct responses) or detailed analyses of applied learning strategies as in Devaine et al. (2017) may allow to compare not only species differences in their spontaneous ability to solve the task, but also species-specific learning curves as well as learning strategies, which might reveal more informative differences.

461 To conclude, our study generated the first systematic results on cognitive abilities in

462 lemurs, and the comparison with haplorhines suggests that in many aspects of the physical and 463 social domain, the average performance in these tests of members of these two lineages do not 
464 differ substantially from each other. These results, which are based on a small sample size, reject

465 the notion of a direct correlation between brain size and cognitive abilities assessed in the PCTB 466 and, may question assumptions of domain-general cognitive skills in primates. Overall, our results

467 strengthen the view that when comparing cognitive abilities among species, it is of vital importance 468 to include a diverse set of tests from both cognitive domains that are applicable to a diverse range 469 of species and taxa (Auersperg et al. 2011, 2013; Burkart et al. 2016; MacLean et al. 2012; Schmitt 470 et al. 2012) and to carefully consider the internal and external validity of the specific tests

471 (Krasheninnikova et al. 2019; Schubiger et al. 2020).

472

473

\section{REFERENCES}

474

Agrillo C, Piffer L, Bisazza A, Butterworth B (2012) Evidence for two numerical systems that are 475 similar in humans and guppies. PLoS ONE 7(2):e31923.

476

Aiello LC, Wheeler P (1995) The expensive-tissue hypothesis: the brain and the digestive system 477 in human and primate evolution. Curr Anthropol 36:199-221.

478

Amici F, Aureli F, Call J (2008) Fission-Fusion dynamics, behavioral flexibility, and inhibitory 479 control in primates. Curr Biol 18:1415-1419.

Amici F, Aureli F, Call J (2010) Monkeys and apes: are their cognitive skills really so different? J Phys Anthropol 143:188-197. doi:10.1002/ajpa.21305

Amici F, Barney B, Johnson VE, Call J, Aureli FA (2012) Modular mind? A test using individual 483

Auersperg AMI, von Bayern AMP, Gajdon GK, Huber L, Kacelnik A (2011) Flexibility in problem solving and tool use of Kea and New Caledonian crows in a multi access box paradigm. PLoS ONE 6(6):e20231. doi:10.1371/journal.pone.0020231

Baden AL, Webster TH, Kamilar JM (2015) Resource seasonality and reproduction predict 
492

493

494

495

496

497

498

499

500

501

502

503

504

505

506

507

508

509

510

511

512

513

514

515

516

517

518

519

520

521

fission-fusion dynamics in black-and-white ruffed lemurs (Varecia variegata). Am J Primatol 78(2):256-279. doi:10.1002/ajp.22507

Benson-Amram S, Dantzer B, Stricker G, Swanson EM, Holekamp KE (2016) Brain size predicts problem-solving ability in mammalian carnivores. PNAS 113(9):2532-2537.

Botting JL, Wiper ML, Anderson JR (2011) Brown (Eulemur fulvus) and ring-tailed lemurs (Lemur catta) use human head orientation as a cue to gaze direction in a food choice task. Folia Primatol 82(3):165-176.

Boyd R, Richerson PJ (1988) Why culture is common, but cultural evolution is rare. Proc Br Acad 88:77-93.

Brotcorne F, Giraud G, Gunst N, Fuentes A, Wandia IN, Beudels-Jamar RC, Poncin P, Huynen M-C, Leca J-B (2017) Intergroup variation in robbing and bartering by long-tailed macaques at Uluwatu Temple (Bali, Indonesia). Primates 58(4):505-516.

Burkart JM, Schubiger MN, van Schaik CP (2016) The evolution of general intelligence. Behav $2016 ; 1-65$.

Byrne RW (1996) Relating brain size to intelligence. In: Mellars P, Gibson K (eds) Modelling the Early Human Mind. McDonald Institute Research Monographs, Cambridge, pp. 49-56.

Byrne RW, Bates LA (2010) Primate social cognition: Uniquely primate, uniquely social, or just unique? Neuron 65:815-830.

Byrne RW, Whiten A (1988) Machiavellian Intelligence: Social expertise and the evolution of intellect in monkeys, apes and humans. Clarendon Press, Oxford.

Chittka L, Geiger K (1995) Can honey bees count landmarks? Anim Behav 49:159-164.

Clutton-Brock TH, Harvey PH (1980) Primates, brains and ecology. J Zool 190:309-323. doi:10.1111/j.1469-7998.1980.tb01430.x

Dammhan M, Kappeler PM (2008) Comparative feeding ecology of sympatric Microcebus berthae and M. murinus. Int J Primatol 29:1567-1589.

Deaner RO, van Schaik C, Johnson V (2006) Do some taxa have better domain-general cognition than others? A metaanalysis of nonhuman primate studies. Evol Psych 4:149-196.

Deaner RO, Isler K, Burkart J, van Schaik C (2007) Overall brain size, and not encephalization quotient, best predicts cognitive ability across non-human primates. Brain, Behav Evol $70: 115-124$. 
522 DeCasien AR, Williams SA, Higham JP (2017) Primate brain size is predicted by diet but not 523 sociality. Nature Ecology \& Evolution, 1, 1-7. http://doi.org/10.1038/s41559-017-0112

524 Deppe AM, Wright PC, Szelistowski WA (2009) Object permanence in lemurs. Anim Cogn $525 \quad 12: 381-388$.

526 Devaine M, San-Galli A, Trapanese C, Bardino G, Hano C, Saint Jalme M, Sebastien Bouret S, 527 Masi S, Daunizeau J (2017) Reading wild minds: A computational assay of Theory of Mind 528

Dunbar RIM, Shultz S (2007) Understanding primate brain evolution. Phil Trans R Soc B 362:649-658. doi:10.1098/rstb.2006.2001

Dunbar RIM, Shultz S (2017) Why are there so many explanations for primate brain evolution? Phil Trans R Soc B 372:20160244. doi:10.1098/rstb.2016.0244

Eberle M, Kappeler PM (2006) Family insurance: kin selection and cooperative breeding in a solitary primate (Microcebus murinus). Behav Ecol Sociobiol 60(4):582-588.

Ehrlich E, Fobes JL, King JE. Prosimian learning capacities. J Hum Evol. 1976; 5:599-617.

Emery N, Seed A, von Bayern AMP, Clayton N (2007) Cognitive adaptations of social bonding in birds. Phil Trans R Soc B 362:489-505.

Fichtel C, Kappeler PM (2010) Human universals and primate symplesiomorphies: establishing the lemur baseline. In: Kappeler PM, Silk J (eds) Mind the Gap: tracing the origins of human universals. Berlin, Springer, pp. 395-426.

Finarelli JA, Flynn JJ (2009) Brain-size evolution and sociality in Carnivora. PNAS 106(23):9345-9349.

547 Fuss T, Bleckmann H, Schluessel V (2014) Visual discrimination abilities in the gray bamboo shark (Chiloscyllium griseum). Zool 117(2):104-111.

549 Gould L, Sussman RW, Sauther ML (2003) Demographic and life-history patterns in a population of ring-tailed lemurs (Lemur catta) at Beza Mahafaly Reserve, Madagascar: a 15-year perspective. Am J Phys Anthropol 120:182-194. doi:10.1002/ajpa.10151

Gumert MD, Malaivijitnond S (2012). Marine prey processed with stone tools by Burmese long- 
553

554

555

556

557

558

559

560

561

562

563

564

565

566

567

568

569

570

571

572

573

574

575

576

577

578

579

580

581

582

583

tailed macaques (Macaca fascicularis aurea) in intertidal habitats. Am J Phys Anthropol 149:447-457.

Heldstab SA, Kosonen ZK, Koski SE, van Schaik C, Isler K (2016) Manipulation complexity in primates coevolved with brain size and terrestriality. Sci Rep 6:24528. doi:10.1038/srep24528

Herrmann E, Call J, Hernández-Lloreda MV, Hare B, Tomasello M (2007) Humans have evolved specialized skills of social cognition: the cultural intelligence hypothesis. Science 317:1360-1366.

Holekamp KE, Sakai ST, Lundrigan BL (2007) Social intelligence in the spotted hyena (Crocuta crocuta). Phil Trans R Soc B 362:523-538.

Holmes SM, Gordon AD, Louis EE, Johnson SE (2016) Fission-fusion dynamics in black-andwhite ruffed lemurs may facilitate both feeding strategies and communal care of infants in a spatially and temporally variable environment. Behav Ecol Sociobiol 70:1949-1960.

Hopkins WD, Russell JL, Schaeffer J (2014). Chimpanzee intelligence is heritable. Curr Biol 24: 1-4.

Humphrey N (1976) The social function of intellect. In: Bateson PPG, Hinde RA (eds) Growing points in ethology. Cambridge University Press, pp. 303-317.

Isler K, Kirk EC, Miller JMA, Albrecht GA, Gelvin BR Martin RD (2008) Endocranial volumes of primate species: scaling analyses using a comprehensive and reliable data set. J Hum Evol 55:967-978.

Itakura S (1996) An exploratory study of gaze-monitoring in nonhuman primates. Jap Psychol Res 38:174-180.

Jerison HJ (1973) Evolution of the brain and intelligence. New York: Academic Press.

Jolly A (1964) Prosimian's manipulation of simple object problems. Anim Behav 12:560-570.

Jolly A (1966a) Lemur social behaviour and primate intelligence. Science 153:501-506.

Jolly A (1966b) Lemur Behavior. Chicago University Press.

Joly M, Micheletta J, De Marco A, Langermans JA, Sterck EH, Waller BM (2017) Comparing physical and social cognitive skills in macaque species with different degrees of social tolerance. Proc Roy Soc B, 284(1862), 20162738.

Jones SM, Brannon EM (2012) Prosimian primates show ratio dependence in spontaneous quantity discriminations. Front Psychol 3:1-8. 
584 Kaminski J, Riedel J, Call J, Tomasello M (2005) Domestic goats, Capra hircus, follow gaze

585

586

587

588

589

590

591

592

593

594

595

596

597

598

599

600

601

602

603

604

605

606

607

608

609

610

611

612

613

614

direction and use social cues in an object choice task. Anim Behav 69:11-18.

Kappeler PM (1987) The acquisition process of a novel behaviour pattern in a group of ring-tailed lemurs (Lemur catta). Primates 28:225-228.

Kappeler PM, Heymann EW (1996) Nonconvergence in the evolution of primate life history and socio-ecology. Biol J Linn Soc 59:297-326.

Kendal RL, Custance DM, Kendal JR, Vale G, Stoinski TS, Rakotomalala NL, Rasamimanana H (2010) Evidence for social learning in wild lemurs (Lemur catta). Learn and Behav 38:220-234.

Kittler K, Schnoell AV, Fichtel C (2015) Cognition in ring-tailed lemurs. Folia Primatol 86:106116.

Kittler K, Kappeler PM, Fichtel C (2018) Instrumental problem solving in three lemur species. J Comp Psychol302: 306-314

Kudo H, Dunbar RIM (2001) Neocortex size and social network size in primates. Anim Behav 62:711-722.

Kummer H, Goodall J (1985). Conditions of innovative behaviour in primates. Phil Trans Roy Soc B 308: 203-214.

Krasheninnikova A, Berardi R, Lind MA, O’Neill, L, von Bayern AM (2019) Primate cognition test battery in parrots. Behaviour, 156(5-8), 721-761

Lahann P (2017) Feeding ecology and seed dispersal of sympatric cheirogaleid lemurs (Microcebus murinus, Cheirogaleus medius, Cheirogaleus major) in the littoral rainforest of south-east Madagascar. J Zool 271:88-98.

Loukola OJ, Perry CJ, Coscos L, Chittka L (2017) Bumblebees show cognitive flexibility by improving on an observed complex behavior. Science 355:833-836.

MacLean EL, Barrickman NL, Johnson EM, Wall CE (2009) Sociality, ecology and relative brain size in lemurs. J Hum Evol 56:471-478.

MacLean EL, Hare B, Nunn CL, Addessi E, Amici F, Anderson RC, Aureli F, Baker JM, Bania AE, Barnard AM, Boogert NJ, Brannon EM, Bray EE, Bray J, Brent LJN, Burkart JM, Call J, Cantlon JF, Cheke LG, Clayton NS, Delgado MM, DiVincenti LJ, Fujita K, Herrmann E, Hiramatsu C, Jacobs LF, Jordan KE, Laude JR, Leimgruber KL, Messer EJE, de A Moura AC, Ostoji L, Picard A, Platt ML, Plotnik JM, Range F, Reader SM, Reddy RB,

Peer) reviewing PDF | (2020:04:48269:1:3:NEW 10 Aug 2020) 
615

616

617

618

619

620

621

622

623

624

625

626

627

628

629

630

631

632

633

634

635

636

637

638

639

640

641

642

643

644

645

Sandel AA, Santos LR, Schumann K, Seed AM, Sewall KB, Shaw RC, Slocombe KE, Su Y, Takimoto A, Tan J, Tao R, van Schaik CP, Viranyi Z, Visalberghi E, Wade JC, Watanabe A, Widness J, Young JK, Zentall TR, Zhao Y (2014) The evolution of selfcontrol. PNAS 111:E2140-E2148.

Maclean EL, Matthews LJ, Hare BA, Nunn CL, Anderson RC, Aureli F, Brannon EM, Call J, Drea CM, Emery NJ, Haun DBM, Herrmann E, Jacobs LF, Platt ML, Rosati AG, Sandel AA, Schroepfer KK, Seed AM, Tan J, Schaik CP, Wobber V (2012) How does cognition evolve? Phylogenetic comparative psychology. Anim Cogn 15:223-238.

MacLean EL, Merritt DJ, Brannon EM (2008) Social complexity predicts transitive reasoning in prosimian primates. Anim Behav 76:479-486.

MacLean EL, Sandel AA, Bray J, Oldenkamp RE, Reddy RB, Hare BA (2013) Group size predicts social but not nonsocial cognition in lemurs. PLoS ONE 8:e66359.

Malassis R, Delfour F (2015) Sea lions' (Zalophus californianus) use of human pointing gestures as referential cues. Learn Behav 43(2):101-112.

ManyPrimates, Altschul DM, Beran MJ, Bohn M, Caspar KR, Fichtel C, Försterling M, Grebe NM, Hernandez-Aguilar RA, Kwok SC, Llorente M, Simpson EA, Szabelska A, Taylor D, van der Mescht J, Völter CJ, Watzek J (2019a). Collaborative open science as a way to reproducibility and new insights in primate cognition research. Japanese Psychological Review, 62, 205-220

ManyPrimates, Altschul DM, Beran MJ, Bohn M, Callj, DeTroy S, Duguid SJ, Egelkamp CL, Fichtel C, Fischer J, Flessert M, Hanus D, Haun DBM, Haux LM, Hernandez-Aguilar RA, Herrmann E, Hopper LM, Joly M, Kano F, Keupp S, Melis AP, Motes Rodrigo A, Ross Sr, Sánchez-Amaro A, Sato Y, Schmitt V, Schweinfurth MK, Seed AM, Taylor D, Völter CJ, Warren E, Watzek J (2019b) Establishing an infrastructure for collaboration in primate cognition research. PLoS ONE 14(10): e0223675

Martin RD (1981) Relative brain size and basal metabolic rate in terrestrial vertebrates. Nature 293:56-60.

Martin RD (1990) Primate Origins and Evolution. A Phylogenetic Reconstruction. London, Chapman \& Hall.

Maslow AH, Harlow HF (1932) Comparative behaviour of primates. II. Delayed reaction tests on primates at Bronx Park Zoo. J Comp Psychol 14:97-107. 
646 Merritt D, MacLean EL, Crawford JC, Brannon EM (2011) Numerical rule-learning in ring-tailed

647

648

649

650

651

652

653

654

655

656

657

658

659

660

661

662

663

664

665

666

667

668

669

670

671

672

673

674

675 lemurs (Lemur catta). Front Psychol 2:41283.

Miklósi Á, Polgárdi R, Topál J, Csányi V (1998) Use of experimenter-given cues in dogs. Anim Cogn 1:113-121.

Milton K (1981) Distribution patterns of tropical plant foods as an evolutionary stimulus to primate mental development. Am Anthropol 83:534-548.

Navarrete A, van Schaik CP, Isler K (2011) Energetics and the evolution of human brain size. Nature 480:91-93.

Nawroth C, Ebersbach M, von Borell E. Are domestic pigs (Sus scrofa domestica) able to use complex human-given cues to find a hidden reward? (2016) Anim Welf 25(2):185-190

O'Mara MT, Hickey CM (2012) Social influences on the development of ringtailed lemur feeding ecology. Anim Behav 84:1547-1555.

Pahl M, Si A, Zhang S (2013) Numerical cognition in bees and other insects. Front Psychol 4(162):1-9.

Pereira ME, Kappeler PM (1997) Divergent systems of agonistic behaviour in lemurid primates. Behav 134:225-274.

Pérez-Barbería FJ, Shultz S, Dunbar RIM (2007) Evidence for coevolution of sociality and relative brain size in three orders of mammals. Evol 61:2811-2821.

Picq J-L (1993) Radial maze performance in young and aged grey mouse lemurs (Microcebus murinus). Primates 34(2):223-226.

Powell LE, Isler K, Barton RA (2017) Re-evaluating the link between brain size and behavioural ecology in primates. Proc R Soc B 284:20171765. doi:10.1098/rspb.2017.1765

Radespiel U, Reimann W, Rahelinirina M, Zimmermann E (2006) Feeding ecology of sympatric mouse lemur species in northwestern Madagascar. Int J Primatol 27(1):311-21.

Reader SM, Hager Y, Laland KN (2011) The evolution of primate general and cultural intelligence. Phil Trans R Soc B 366:1017-1027. doi:10.1098/rstb.2010.0342

Reader SM, Laland KN (2002) Social intelligence, innovation, and enhanced brain size in primates. PNAS 99:4436-4441.

Rosati AG, Rodriguez K, Hare B (2014) The ecology of spatial memory in four lemur species. Anim Cogn 17:947-961. 
676 Rosati AG (2017) Foraging cognition: Reviving the ecological intelligence hypothesis. Trends Cogn Sci 21(9):691-702. doi:10.1016/j.tics.2017.05.011

678 Sandel AA, MacLean EL, Hare B (2011) Evidence from four lemur species that ringtailed lemur 679 social cognition converges with that of haplorhine primates. Anim Behav 81:925-931.

680

681

682

683

684

685

686

687

688

689

690

691

692

693

694

695

696

697

698

699

700

701

702

703

704

705

706

Santos LR, Barnes JL, Mahajan N (2005a) Expectations about numerical events in four lemur species (Eulemur fulvus, Eulemur mongoz, Lemur catta and Varecia rubra). Anim Cogn $8: 253-262$.

Santos LR, Mahajan N, Barnes JL (2005b) How prosimian primates represent tools: experiments with two lemur species (Eulemur fulvus and Lemur catta). J Comp Psych 119:394-403.

Schluessel V, Herzog H, Scherpenstein M (2015) Seeing the forest before the trees - spatial orientation in freshwater stingrays (Potamotrygon motoro) in a hole-board task. Behav Proc 119:105-115.

Schmitt V, Pankau B, Fischer J (2012) Old world monkeys compare to apes in the Primate Cognition Test Battery. PLoS ONE 7(4):e32024.

Schnoell AV, Fichtel C (2012) Wild redfronted lemurs (Eulemur rufifrons) use social information to learn new foraging techniques. Anim Cogn 15:505-516.

Schubiger MN, Kissling A, Burkart JM (2016) How task format affects cognitive performance: A memory test with two species of New World monkeys. Anim Behav 121, 33-39.

Schubiger MN, Fichtel C, Burkart JM (2020) Validity of cognitive tests in nonhuman animals: pitfalls and prospects. Front Psychol, in press.

Shepherd SV, Platt ML (2008) Spontaneous social orienting and gaze following in ringtailed lemurs (Lemur catta). Anim Cogn 11:13-20. doi:10.1007/s10071-007-0083-6

Shettleworth SJ (2010) Cognition, Evolution and Behavior. New York: Oxford University Press.

Shultz S, Dunbar RIM (2006) Both social and ecological factors predict ungulate brain size. Proc R Soc B 273:207-215.

Shultz S, Dunbar RIM (2007) The evolution of the social brain: anthropoid primates contrast with other vertebrates. Proc R Soc B 274:2429-2436.

Spearman C (1904) "General intelligence", objectively determined and measured. American J Psychol 15(2):201-292.

Stoinski TS, Drayton LA, Price EE (2011) Evidence of social learning in black-and-white ruffed lemurs (Varecia variegata). Biol Lett, 7(3), 376-379. 
707 Sussmann RW (1991) Demography and social organization of free-ranging Lemur catta in the

708

709

710

711

712

713

714

715

716

717

718

719

720

721

722

723

724

725

726

727

728

729

730

731

732

733

734

735

736

Beza Mahafaly Reserve, Madagascar. Am Journal Phys Anthropol 84:43-58.

Tomasello M, Call J (1997) Primate Cognition. Oxford University Press, New York.

Torigoe T (1985) Comparison of object manipulation among 74 species of non-human primates. Primates 26:182-194.

Tschudin A, Call J, Dunbar RIM, Harris G, van der Elst C (2001) Comprehension of signs by dolphins (Tursiops truncatus). J Comp Psychol 115:100-105.

Vasey N (2003) Varecia, ruffed lemurs. In: Goodman SM, Benstead JP (eds) The natural history of Madagascar Chicago. University Press, pp. 1332-1336.

van Horik J, Emery NJ (2011) Evolution of cognition. Wiley Interdisciplinary Reviews: Cognitive Science, 2(6), 621-633.

van Schaik CP, Fox EA, Fechtman LT (2003) Individual variation in the rate of use of tree-hole tools among wild orang-utans: implications for hominin evolution. J Hum Evol 44(1):1123.

Wallis LJ, Range F, Müller CA, Serisier S, Huber L, Virányi Z (2015) Training for eye contact modulates gaze following in dogs. Anim Behav 106:27-35.

Whiten A, van Schaik CP (2007) The evolution of animal 'cultures' and social intelligence. Phil Trans R Soc B 362(1480):603-620.

Yoder AD, Cartmill M, Ruvolo M, Smith K, Vilgalys R (1996) Ancient single origin for Malagasy primates. Proc Nat Acad Sci USA 93:5122-5126.

Yoder AD, Yang Z (2004) Divergence dates for Malagasy lemurs estimated from multiple gene loci: geological and evolutionary context. Mol Ecol 13:757-773.

\section{ACKNOWLEDGEMENTS}

We are grateful to Silvio Dietzel and the "Erlebnispark Affenwald" for permission to work with the lemurs. We would also like to thank Esther Herrmann and Vanessa Schmitt for sharing the PCTB performance data of the great apes and monkeys with us. Furthermore, we are grateful to Ulrike Walbaum, Anna Zango Palau, Luise Zieba and Lluis Socias Martinez for helping with the

Peer] reviewing PDF | (2020:04:48269:1:3:NEW 10 Aug 2020) 
737 experiments and inter-observer coding the videos. Thanks to Sarah Hartung, Henry Benseler and

738 Ramona Lenzner-Pollmann for taking care of the animals. This study was supported by the

739 German Science Foundation (Deutsche Forschungsgemeinschaft, awarded to CF: FI 929/8-1). We

740 are also grateful to Andrew Zamora, Louise Barrett and an anonymous reviewer for very

741 constructive comments on an earlier version of the manuscript.

742

743 AUTHORS' CONTRIBUTIONS

744 C.F. and K.D. have a shared first-authorship, they conceived the study and analysed the data. K.D.

745 conducted the experiments. C.F., K.D. and P.M.K. wrote the manuscript. All authors gave final

746 approval for publication.

747

748 COMPETING INTERESTS

749 We have no competing interests. 


\section{$750 \quad$ Figure legends}

751

752 Figure 1 Average performance of the three lemur species in all tasks of the PCTB. Represented 753 are medians (black bars), interquartile ranges (boxes), and outliers (circles).

754

755 Figure 2 Average performance of apes \& monkeys (red and orange colours) and lemurs (blue and 756 grey colours) in the two cognitive domains. Represented are medians (black bars), interquartile 757 ranges (boxes), and outliers (circles).

758

759 Figure 3 Average performance of apes \& monkeys (red and orange colours) and lemurs (blue and 760 grey colours) over the six scales. Represented are medians (black bars), interquartile ranges 761 (boxes), and outliers (circles). 


\section{Table 1 (on next page)}

Socio-ecological traits

Summary of the most important socio-ecological traits for the seven non-human primate species 
1 Table 1 Summary of the most important socio-ecological traits of the seven non-human primate species discussed in $\frac{2}{3}$ the present study.

\begin{tabular}{c|cccccc}
\hline species & $\begin{array}{c}\mathbf{N} \\
\text { (present study) }\end{array}$ & $\begin{array}{c}\text { ECV } \\
\text { (cc) }\end{array}$ & $\begin{array}{c}\text { \% } \\
\text { fruit }\end{array}$ & $\begin{array}{c}\text { dietary } \\
\text { breadth }\end{array}$ & $\begin{array}{c}\text { social } \\
\text { system }\end{array}$ & $\begin{array}{c}\text { average } \\
\text { group size }\end{array}$ \\
\hline $\begin{array}{c}\text { chimpanzees } \\
\text { (Pan troglodytes) } \\
\text { orangutans }\end{array}$ & 106 & 368.4 & 66 & 6 & group & 47.6 \\
$\begin{array}{c}\text { (Pongo pygmaeus) } \\
\text { olive baboons }\end{array}$ & 32 & 377.4 & 64 & 6 & solitary & 1.5 \\
$\begin{array}{c}\text { (Papio anubis) } \\
\text { long-tailed macaques } \\
(\text { Macaca fascicularis) }\end{array}$ & $10-13$ & 64 & 66.9 & 5 & group & 26 \\
$\begin{array}{c}\text { ruffed lemurs } \\
\text { (Varecia } \text { variegata) } \\
\text { ring-tailed lemurs }\end{array}$ & 13 & 32.1 & 92 & 4 & group & 6 \\
$\begin{array}{c}\text { (Lemur catta) } \\
\text { grey mouse lemurs }\end{array}$ & $26-27$ & 22.9 & 54 & 5 & group & 24 \\
\hline Microcebus murinus $)$ & $9-16$ & 1.6 & 31.3 & 4 & solitary & 1 \\
\hline
\end{tabular}

$\mathrm{n}=$ number of individuals, $\mathrm{ECV}=$ endocranial volume (absolute brain size), $\%$ fruit=percentage of fruit in the diet; Data from: Baden et al. 2015; Dammhan and Kappeler 2006; Herrmann et al. 2007; Isler et al. 2008; Lahann 2007; MacLean et al. 2014; Radespiel et al. 2006; Schmitt et al. 2012. 


\section{Table 2 (on next page)}

Proportion of correct responses of the three lemur species

Summary of the mean proportions of correct responses of the three lemur species in all tasks and scales of the PCTB 
1 Table 2 Summary of the mean proportions of correct responses of the three lemur species in all tasks and scales of the PCTB.

\begin{tabular}{|c|c|c|c|c|c|c|c|c|c|c|c|c|c|c|c|c|c|}
\hline & \multirow[b]{2}{*}{ trials } & \multirow[b]{2}{*}{ chance } & \multicolumn{5}{|c|}{ Ruffed lemurs } & \multicolumn{5}{|c|}{ Ring-tailed lemurs } & \multicolumn{5}{|c|}{ Mouse lemurs } \\
\hline & & & n & M & $\operatorname{adj} p$ & SD & $\begin{array}{c}95 \% \\
\text { CI }\end{array}$ & n & M & $\operatorname{adj} p$ & SD & $\begin{array}{c}95 \% \\
\text { CI }\end{array}$ & n & M & $\operatorname{adj} p$ & SD & $\begin{array}{c}95 \% \\
\text { CI }\end{array}$ \\
\hline \multicolumn{18}{|l|}{ Physical domain } \\
\hline$\overline{\text { Space }}$ & & & & 46.8 & & 8 & 51,58 & & 44.2 & & 7 & 42.47 & & 50.8 & & 7 & 47,55 \\
\hline Spatial memory & 6 & 33 & 13 & 53.9 & 0.017 & 23 & 42,66 & 27 & 55.6 & 0.001 & 17 & 49,62 & 15 & 66.7 & 0.004 & 18 & 58,68 \\
\hline Object permanence & 18 & 33 & 13 & 47.9 & 0.006 & 12 & 41,55 & 27 & 38.3 & 0.112 & 15 & 32,44 & 12 & 42.1 & 0.074 & 10 & 36,48 \\
\hline Rotation & 18 & 33 & 13 & 45.3 & 0.014 & 10 & 40,51 & 26 & 41.0 & 0.002 & 9 & 37,45 & 12 & 47.7 & 0.008 & 9 & 43,53 \\
\hline Transposition & 18 & 33 & 13 & 40.2 & 0.052 & 13 & 33,47 & 27 & 42.2 & 0.001 & 11 & 38,46 & 12 & 41.2 & 0.019 & 12 & 35,48 \\
\hline Quantity & & & & 66.4 & & 12 & 60,73 & & 58.5 & & 11 & 54,63 & & 63.9 & & 6 & 60,68 \\
\hline Relative numbers & 16 & 50 & 13 & 62.0 & 0.006 & 7 & 58,66 & 27 & 60.4 & 0.007 & 10 & 57,64 & 9 & 66.0 & 0.019 & 11 & 59,73 \\
\hline Addition numbers & 14 & 50 & 13 & 70.9 & 0.014 & 20 & 60,82 & 26 & 60.2 & 0.003 & 13 & 55,65 & 9 & 61.9 & 0.019 & 8 & 57,67 \\
\hline Causality & & & & 51.0 & & 7 & 47,55 & & 48.6 & & 7 & 46,51 & & 44.0 & & 4 & 42,46 \\
\hline Noise & 12 & 50 & 13 & 63.5 & 0.015 & 13 & 56,71 & 27 & 59.3 & 0.002 & 10 & 55,63 & 15 & 50.0 & 0.958 & 17 & 41,59 \\
\hline Shape & 12 & 50 & 13 & 76.9 & 0.006 & 15 & 69,85 & 27 & 72.8 & 0.001 & 10 & 69,77 & 15 & 70.6 & 0.004 & 12 & 65,77 \\
\hline Tool use & 1 & - & 13 & 0.0 & - & - & - & 27 & 3.7 & - & 19 & $-4,11$ & 15 & 0.0 & - & - & - \\
\hline Tool properties & 30 & 50 & 13 & 63.6 & 0.013 & 12 & 57,70 & 27 & 58.6 & 0.001 & 8 & 56,62 & 15 & 55.6 & 0.040 & 9 & 51,60 \\
\hline \multicolumn{18}{|l|}{ Social domain } \\
\hline$\overline{\text { Social learning }}$ & 3 & - & 13 & 0.0 & - & - & - & 26 & 0.0 & & - & - & 12 & 0.0 & & - & - \\
\hline Communication & & & & 53.1 & & 12 & 47,60 & & 49.6 & & 11 & 46,54 & & 52.1 & & 9 & 47,57 \\
\hline Comprehension & 18 & 50 & 13 & 70.9 & 0.006 & 10 & 66,76 & 27 & 70.8 & 0.001 & 13 & 66,76 & 13 & 65.4 & 0.008 & 11 & 59,72 \\
\hline Pointing cups & 8 & 50 & 13 & 53.9 & 0.220 & 9 & 49,59 & 27 & 55.1 & 0.050 & 12 & 51,59 & 15 & 68.3 & 0.008 & 16 & 60,76 \\
\hline Attentional state & 4 & - & 13 & 34.6 & - & 28 & 19,50 & 26 & 21.2 & - & 22 & 13,30 & 14 & 25.0 & - & 22 & 14,36 \\
\hline Theory of mind & & & & 43.7 & & 10 & 45,57 & & 56.8 & & 18 & 50,64 & & 51.4 & & 11 & 39,49 \\
\hline Gaze following & 9 & $20(\mathrm{bl})$ & 13 & 23.9 & 0.326 & 17 & 15,33 & 27 & 30.0 & 0.340 & 33 & 18,42 & 15 & 11.1 & 0.713 & 17 & 2,20 \\
\hline Intentions & 12 & 50 & 13 & 78.9 & 0.006 & 13 & 72,86 & 27 & 83.6 & 0.001 & 15 & 78,89 & 15 & 71.1 & 0.004 & 10 & 66,76 \\
\hline
\end{tabular}

2 Numbers in boldface: Significant deviations from chance level (Wilcoxon tests); Trials=number of trials per task; chance=chance-level for each task; $\mathrm{n}=$ number of participating

3 individuals; $\mathrm{M}=$ means of performance; adj= adjusted $\mathrm{p}$-values (Benjamini-Hochberg-corrections); $\mathrm{SD}=$ standard deviation; $\mathrm{CI}=\mathrm{confidence}$ interval; $\mathrm{bl}=\mathrm{baseline}$ calculated from

4 control condition. 


\section{Table 3(on next page)}

Species differences in the six cognitive scales

Univariate analyses for the species differences for the six cognitive scales. 
1

3

4
5
6

Table 3 Univariate analyses for the species differences for the six cognitive scales.

\begin{tabular}{lccc}
\hline ANOVAs & Df & $\begin{array}{c}\boldsymbol{F} \text { - } \\
\text { value }\end{array}$ & P-value \\
\hline Quantity & 6 & 3.49 & $\mathbf{0 . 0 0 2 6} * *$ \\
Communication & 6 & 2.10 & 0.0549 \\
\hline Kruskal-Wallis & Df & $\chi^{\mathbf{2}}$ & P-value \\
tests & 6 & 111.68 & $<\mathbf{0 . 0 0 1} * * *$ \\
\hline Space & 6 & 68.59 & $<\mathbf{0 . 0 0 1} * * *$ \\
Causality & 6 & 20.17 & $\mathbf{0 . 0 0 2 6} * *$ \\
Social learning & 6 & 55.08 & $<\mathbf{0 . 0 0 1} * * *$ \\
Theory of Mind & & \\
\hline
\end{tabular}

$* *<0.01 ; * * *<0.001-$ significance levels 


\section{Table 4 (on next page)}

Comparisons of performance among the seven non-human primate species

Comparisons of performance among the seven non-human primate species for all six scales of the PCTB. Presented are the results of post hocmultiple comparisons (Bonferroni); significant results are in boldface. Causality II: The scale causality without the tools use task. 
1 Table 4 Comparisons of performance among the seven non-human primate species for all six scales of the PCTB. 2 Presented are the results of post hoc multiple comparisons (Bonferroni); significant results are in boldface. Causality 3 II: The scale causality without the tools use task.

\begin{tabular}{|c|c|c|c|c|c|c|c|}
\hline & Space & Quantity & Causality & $\begin{array}{c}\text { Causality } \\
\text { II }\end{array}$ & $\begin{array}{c}\begin{array}{c}\text { Social } \\
\text { learning }\end{array} \\
\end{array}$ & $\begin{array}{c}\text { Commun- } \\
\text { ication }\end{array}$ & $\begin{array}{l}\text { Theory } \\
\text { of Mind }\end{array}$ \\
\hline Chimp - Orang & $<0.001$ & 0.275 & $<0.001$ & 1 & 1 & 1 & 1 \\
\hline Chimp - Baboon & 1 & 1 & 0.003 & 1 & 1 & 1 & 0.082 \\
\hline Chimp - Macaque & $<0.001$ & 1 & $<0.001$ & 1 & 0.699 & 1 & $<\mathbf{0 . 0 0 1}$ \\
\hline Chimp - Ruffed lemur & $<0.001$ & 1 & $<0.001$ & 1 & 0.352 & 1 & 0.077 \\
\hline Chimp - Ring-tailed lemur & $<0.001$ & $<0.001$ & $<0.001$ & 1 & 0.025 & 0.29 & $<0.001$ \\
\hline Chimp - Mouse lemur & $<0.001$ & 1 & $<0.001$ & 0.041 & 0.229 & 1 & 1 \\
\hline Orang - Baboon & 1 & 1 & 1 & 1 & 1 & 0.677 & 0.014 \\
\hline Orang - Macaque & 1 & 1 & 0.433 & 1 & 1 & 1 & $<0.001$ \\
\hline Orang - Ruffed lemur & 0.004 & 1 & 1 & 0.560 & 1 & 1 & 0.009 \\
\hline Orang - Ring-tailed lemur & $<0.001$ & 1 & 0.643 & 1 & 0.919 & 1 & $<\mathbf{0 . 0 0 1}$ \\
\hline Orang - Mouse lemur & 0.237 & 1 & 0.046 & 0.918 & 1 & 1 & 1 \\
\hline Baboon - Macaque & 0.176 & 1 & 1 & 1 & 1 & 0.591 & 1 \\
\hline Baboon - Ruffed lemur & 0.001 & 1 & 1 & 1 & 1 & 0.653 & 1 \\
\hline Baboon - Ring-tailed lemur & $<0.001$ & 1 & 1 & 1 & 1 & 0.094 & 1 \\
\hline Baboon - Mouse lemur & 0.023 & 1 & 1 & 1 & 1 & 0.424 & 0.816 \\
\hline Macaque - Ruffed lemur & 1 & 1 & 1 & 1 & 1 & 1 & 1 \\
\hline Macaque - Ring-tailed lemur & 0.074 & 0.307 & 1 & 1 & 1 & 1 & 1 \\
\hline Macaque - Mouse lemur & 1 & 1 & 1 & 1 & 1 & 1 & $\mathbf{0 . 0 3 3}$ \\
\hline Ruffed lemur - Ring-tailed lemur & 1 & 0.409 & 1 & 1 & 1 & 1 & 1 \\
\hline Ruffed lemur - Mouse lemur & 1 & 1 & 1 & 0.008 & 1 & 1 & 1 \\
\hline Ring-tailed lemur - Mouse lemur & 1 & 1 & 1 & 0.106 & 1 & 1 & 0.036 \\
\hline
\end{tabular}


Figure 1

Performance in the PCTB of the three lemur species

Average performance of the three lemur species in all tasks of the PCTB. Represented are medians (black bars), interquartile ranges (boxes), and outliers (circles). 
a) Space

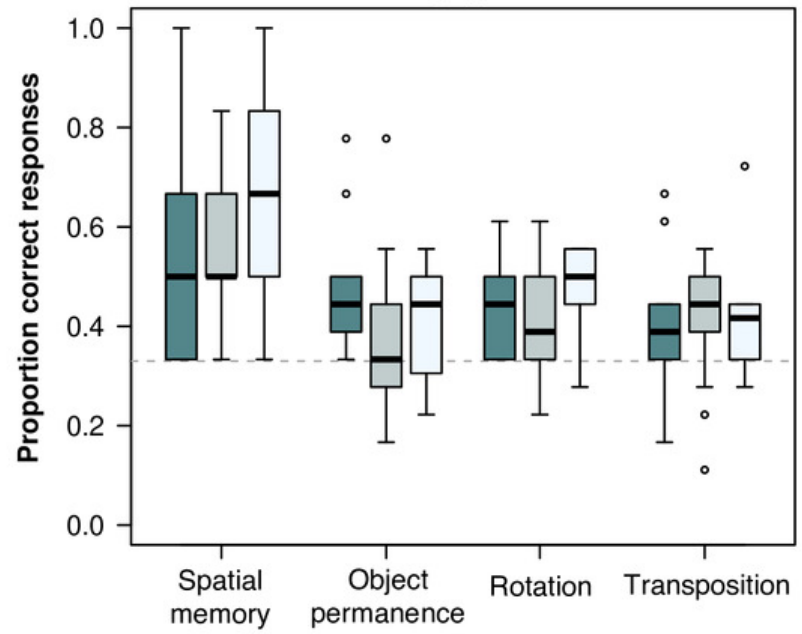

c) Causality

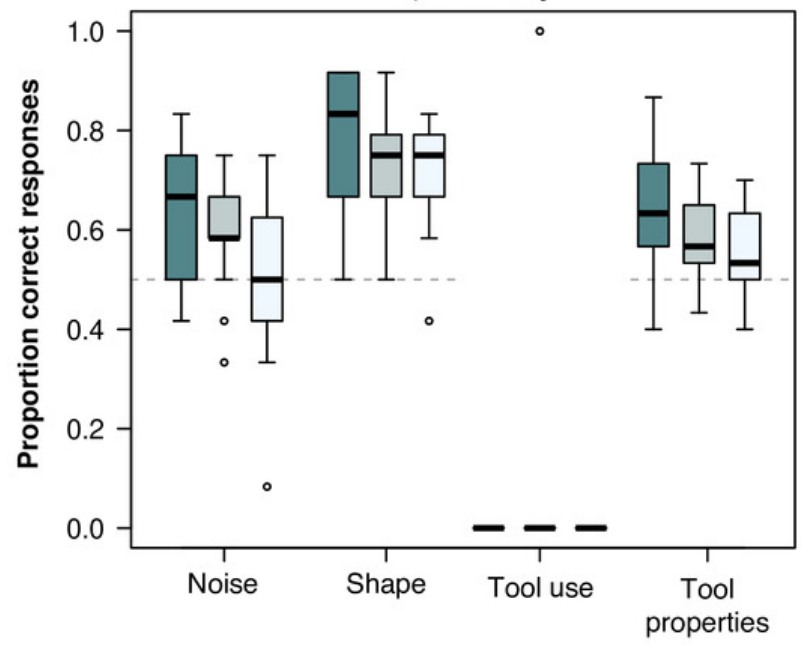

e) Communication

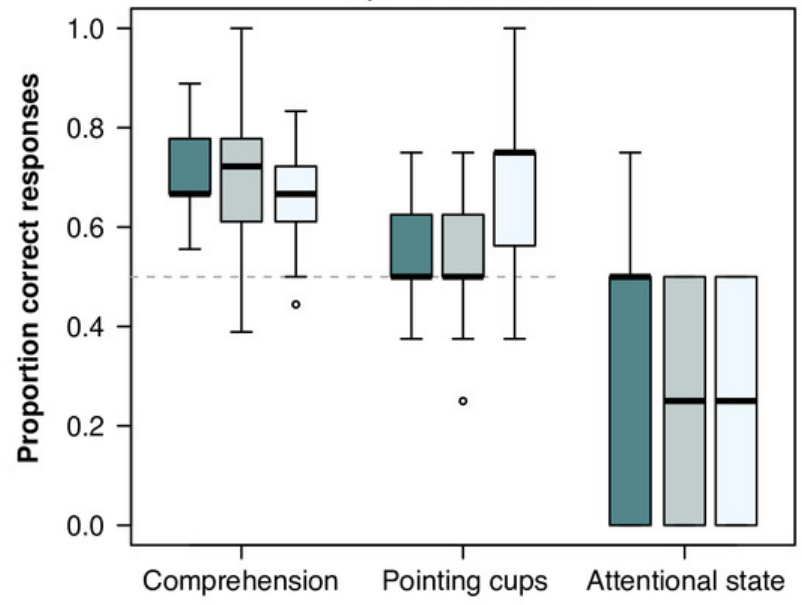

b) Quantities

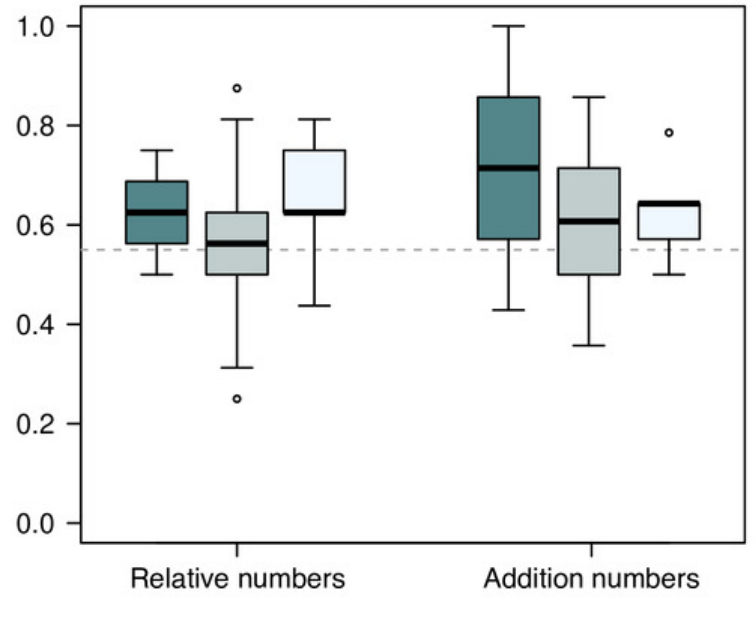

d) Social learning

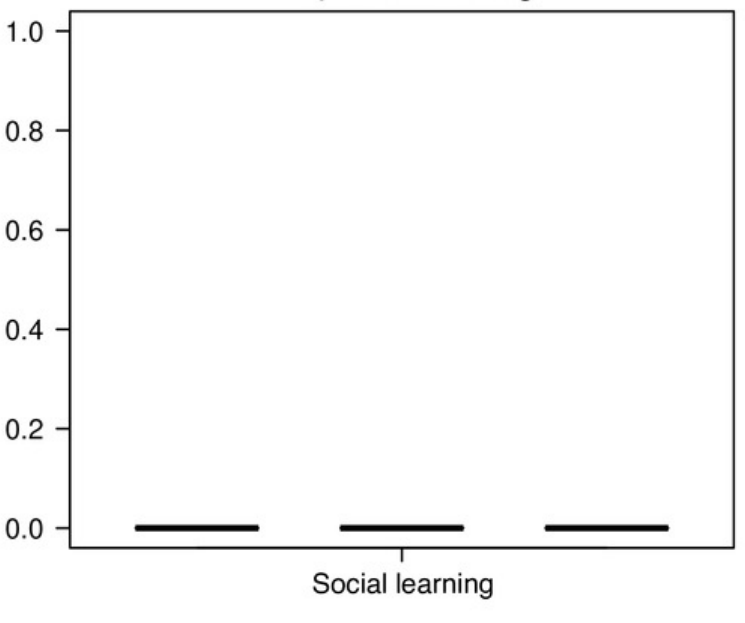

f) Theory of mind

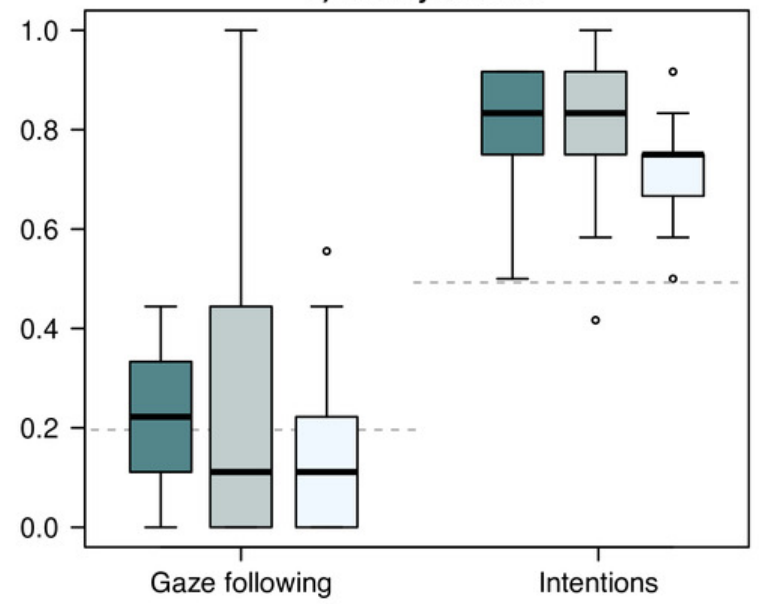

Ruffed lemurs

Ring-tailed lemurs

Mouse lemurs 
Figure 2

Performance of the seven primate species in the physical and social domain

Average performance of apes $\&$ monkeys (red and orange colours) and lemurs (blue and grey

colours) in the two cognitive domains. Represented are medians (black bars), interquartile ranges (boxes), and outliers (circles). 


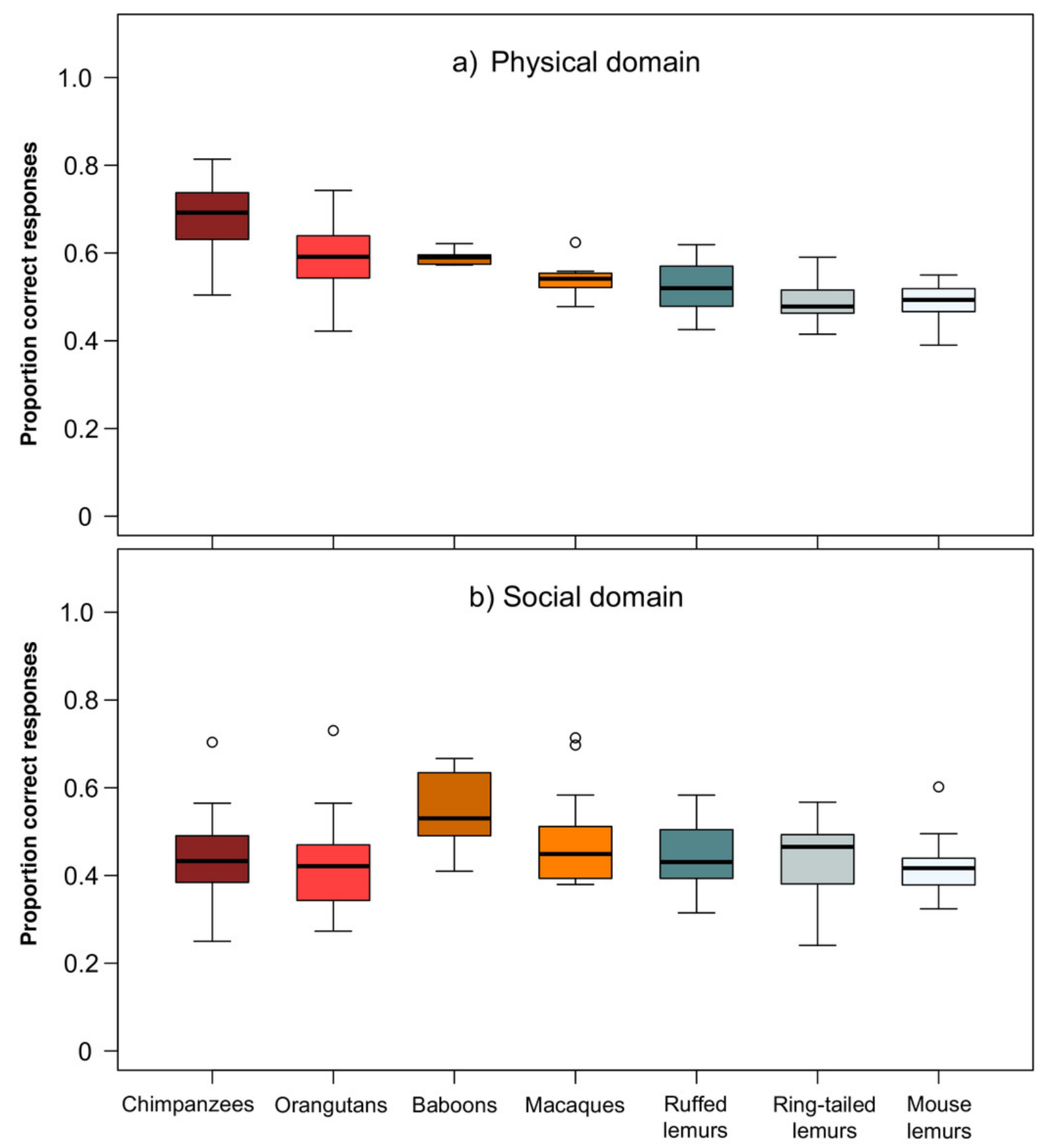


Figure 3

Performance of the seven primate species in the six cognitive scales

Average performance of apes $\&$ monkeys (red and orange colours) and lemurs (blue and grey colours) over the six scales. Represented are medians (black bars), interquartile ranges (boxes), and outliers (circles). 

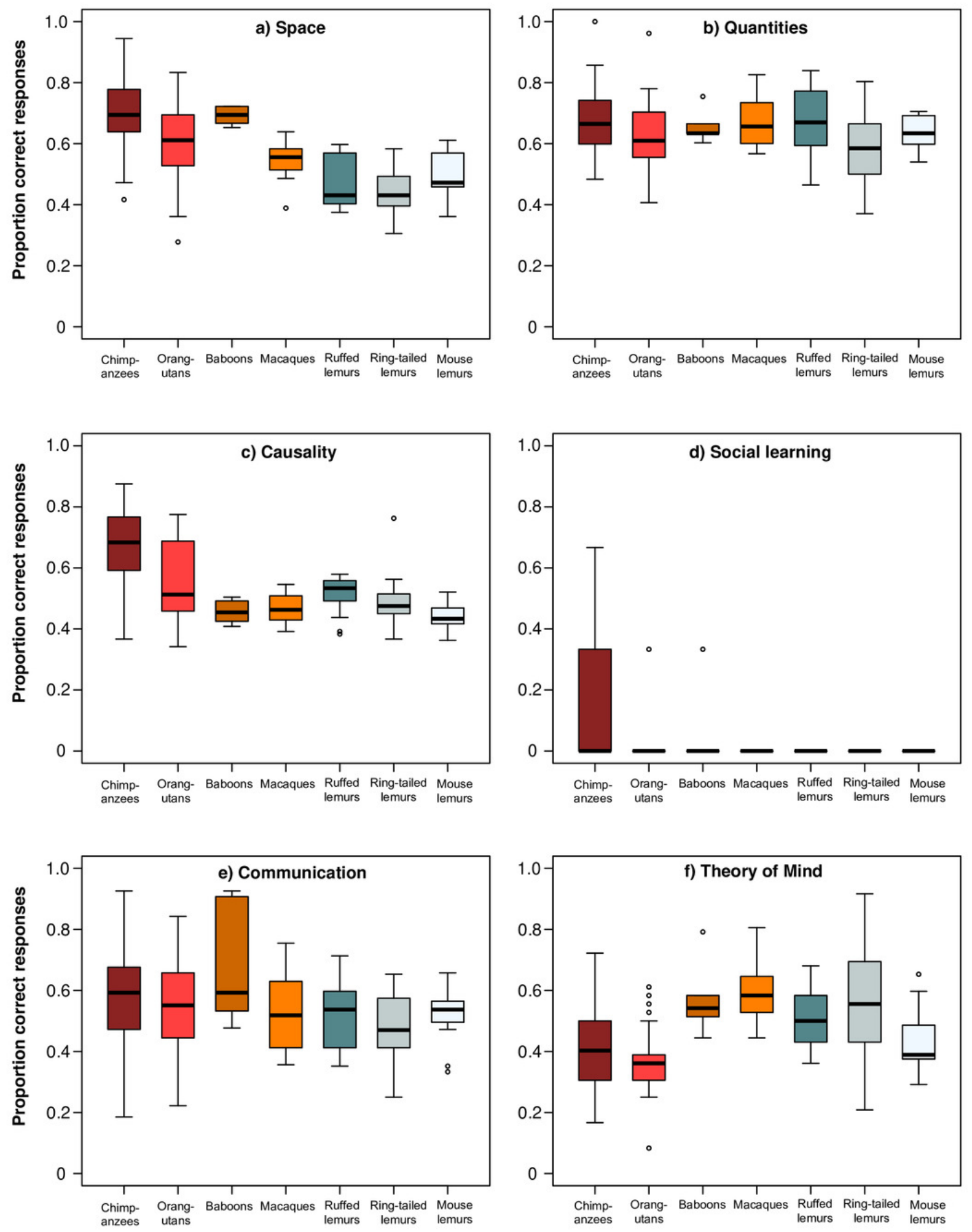